\title{
The MNS16A polymorphism in the TERT gene in peri-centenarians from the Han Chinese population
}

\author{
LIU LiNa ${ }^{1 \dagger}$, WANG ChengYe ${ }^{2 \dagger}$, LU Xiang $^{1}$, XIAO FuHui $^{1}$, WANG HuaWei ${ }^{1}$, YANG LiQin $^{1}$, \\ XU Liang You ${ }^{3} \&$ KONG QingPeng ${ }^{*}$ \\ ${ }^{1}$ State Key Laboratory of Genetic Resources and Evolution, Kunming Institute of Zoology, Chinese Academy of Sciences, Kunming 650223, \\ China; \\ ${ }^{2}$ Key Laboratory of Cultivating and Utilization of Resource Insects of State Forestry Administration, Research Institute of Resource Insects, \\ Chinese Academy of Forestry, Kunming 650224, China; \\ ${ }^{3}$ Dujiangyan Longevity Research Center, Dujiangyan 611830, China
}

Received November 25, 2013; accepted May 7, 2014; published online August 22, 2014

\begin{abstract}
MNS16A, a variable number of tandem repeats polymorphism in the TERT gene, has been suggested to regulate telomerase activity. As telomerase activity has been reported to be related to life-span, we hypothesized that this polymorphism might affect human longevity by controlling the length of the telomere. To test this hypothesis, we collected 446 unrelated pericentenarian individuals (age $\geqslant 90$, mean $94.45 \pm 3.45$ years) and 332 normal controls (age 22-53, mean 35.0 \pm 12.0 years) from Dujiangyan, Sichuan, China. We typed the MNS16A polymorphism in both groups, and compared the allele and genotype frequencies between the peri-centenarian and control groups using the chi-squared test. There was no significant difference between the peri-centenarian and control groups. Thus, the MNS16A polymorphism in TERT might not influence human life-span, at least in the Han Chinese population studied here.
\end{abstract}

telomerase, longevity, MNS16A polymorphism, peri-centenarian

Citation: $\quad$ Liu LN, Wang CY, Lu X, Xiao FH, Wang HW, Yang LQ, Xu LY, Kong QP. The MNS16A polymorphism in the TERT gene in peri-centenarians from the Han Chinese populations. Sci China Life Sci, 2014, 57: 1024-1027, doi: 10.1007/s11427-014-4723-1

Aging is a complex physical process that encompasses a variety of changes in many bodily functions, such as decreased cellular proliferative potential, a less efficient immune system, and changed endocrine system functions [1-3]. During aging, genetic and environmental factors interact with each other and both provide major contributions. Genetic factors are particularly crucial in the aging process and could greatly influence the life-span [4-6]. Mitchell et al. [7] estimated a $25 \%$ heritability for life-span in an Amish population from Lancaster County, Pennsylvania, USA.

Telomeres are structures that cap the distal ends of

$\dagger$ Contributed equally to this work

*Corresponding author (email: kongqp@mail.kiz.ac.cn) chromosomes, protecting them from degradation, end-toend fusions, rearrangements, and chromosome attrition [8]. The length of the telomere, which is maintained by telomerase, determines the proliferative potential of cells $[9,10]$. Telomerase is a reverse transcriptase that elongates the TTAGGG repeats of telomeres and thus maintain the ends of chromosomes and the proliferative potential of cells $[11,12]$. Intriguingly, high telomerase activity, resulting in lengthened telomeres, was reported to be related to longer life-spans in mice [13] and in birds [14]. Furthermore, it has been suggested that high human telomerase activity is associated with better maintenance of telomere length, which may confer healthy aging and exceptional longevity in humans $[15,16]$. 
Telomerase is a holoenzyme, composed of an RNA component, a catalytic protein subunit, and other telomerase-associated proteins [17]. Its catalytic subunit (telomerase reverse transcriptase, TERT) is the core component responsible for its enzymatic activity [18], and the expression level of TERT is closely associated with telomerase activity $[19,20]$. It can be speculated that functional polymorphisms in the TERT gene might be biological candidates related to longevity by influencing the expression of TERT.

Recently, a variable number of tandem repeats polymorphism, MNS16A, located downstream of the human TERT gene on chromosome $5 \mathrm{p} 15.33$, was reported to have an effect on TERT expression and telomerase activity [21]. The region containing MNS16A was found to have promoter activity on TERT expression, and the promoter-like activity was influenced by the length of the MNS16A tandem repeat. Thus, the MNS16A length polymorphism could influence the activity of telomerase by regulating the expression of TERT [21].

We hypothesized that the MNS16A polymorphism might be a genetic factor related to longevity. To test this hypothesis, we performed an association study in a Han Chinese population.

\section{Materials and methods}

\subsection{Subjects}

A total of 446 unrelated peri-centenarian individuals (age $\geqslant 90$, mean $94.45 \pm 3.45$ years) were recruited from Dujiangyan, Sichuan, China. As reported in our previous studies [22-24], the age of the subjects was certified by the Chinese Fifth National Census, and was also supported by the number of generations of their offspring $(\geqslant 3)$, and local village records. Only subjects whose age was supported by the government identity record and local village record, and who fulfilled the required number of offspring generations, were included. The demographic characteristics of the individuals have been described in our previous work [22-24]. At the same time, we recruited 332 healthy local younger people from the same area (age 22-53, mean 35.0 \pm 12.0 years) to be normal controls. All participants signed informed consent. This research was approved by the Ethics Committee on Human Experimentation of Kunming Institute of Zoology, Chinese Academy of Sciences. The study was performed in accordance with the Declaration of Helsinki and its subsequent amendments.

\subsection{Polymorphism genotyping}

Peripheral blood was collected from the participants and genomic DNA was extracted using the standard phenol/chloroform method. The MNS16A polymorphism was genotyped by PCR with primers as previously described [21]: forward primer: 5'-AGGATTCTGATCTCTGAAG-
GGTG-3'; reverse primer: 5'-TCTGCCTGAGGAAGGACGTATG-3'; GenBank: AF128894. 1. Briefly, PCR was performed in a total volume of $20 \mu \mathrm{L}$ with an initial denaturing step of $5 \mathrm{~min}$ at $95^{\circ} \mathrm{C}$, followed by 35 cycles of $30 \mathrm{~s}$ at $95^{\circ} \mathrm{C}, 45 \mathrm{~s}$ at $61^{\circ} \mathrm{C}$, and $1 \mathrm{~min}$ at $72^{\circ} \mathrm{C}$, and a final extension step of $10 \mathrm{~min}$ at $72^{\circ} \mathrm{C}$. The PCR products were separated on an ethidium bromide-stained 3.0\% agarose gel, visualized with UV light, and photographed. Ten percent of the samples were re-genotyped and subjected to direct sequencing to confirm the accuracy of the genotyping.

\subsection{Statistical analysis}

The genotype and allele frequencies in both groups were compared by Pearson's chi-squared test. Fisher's exact test was applied when there were low counts $(<5)$ in the data. The $P$-value is two-tailed. When the $P$-value was $<0.05$, it was considered to be statistically significant and was further subjected to Bonferroni correction for multiple testing. Analyses were performed using SPSS software (version 17.0, SPSS Inc., Chicago, IL, USA). A test for HardyWeinberg equilibrium for the MNS16A polymorphism in the peri-centenarian and control groups was performed using GENEPOP software [25].

\section{Results and discussion}

We genotyped the MNS16A polymorphism in the TERT gene in 446 peri-centenarians and 332 matched young individuals. We observed three length variants at this locus: 243, 272, and 302 bp (Figure 1), which together formed five genotypes (Table 1). The genotype frequencies in the pericentenarian and control populations did not deviate from Hardy-Weinberg equilibrium $(P>0.05)$, in accordance with our previous work [22-24].

The proportion of homozygote and the genotype and allele frequencies of MNS16A are listed in Table 1 . The most common genotype was 302/302, followed by $302 / 243$, $302 / 272,272 / 243$, and $243 / 243$. The 302-bp allele had the highest frequency of $94.28 \%$ in the longevity group, with a very similar frequency $(93.67 \%)$ in the control group. Interestingly, we did not observe the previously reported 333-bp

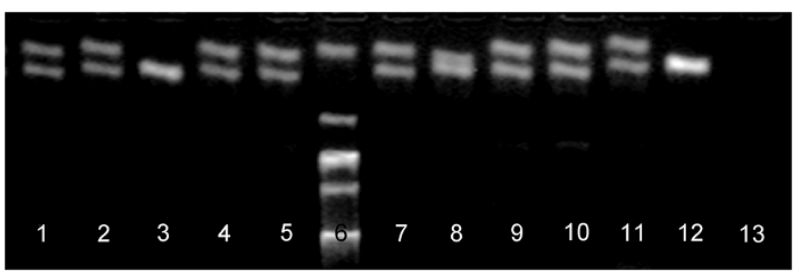

Figure 1 Genotype patterns of TERT MNS16A. The different MNS16A allele lengths were named according to their PCR fragment size. Lanes 1, 2, 4, 5, 7, 9-11: 302/243; lanes 3 and 12: 302/302; lane 6: DNA marker; lane 8: 302/272; lane 13: negative control. 
Table 1 Genotype frequency, allele distribution, and homozygote proportion for MNS16A in the peri-centenarian and control groups

\begin{tabular}{|c|c|c|c|c|c|}
\hline \multirow{2}{*}{$\begin{array}{c}\text { Genotype } \\
302 / 302\end{array}$} & \multicolumn{2}{|c|}{ Peri-centenarian $(N=446)$} & \multicolumn{2}{|c|}{ Controls $(N=332)$} & \multirow{2}{*}{$\begin{array}{c}P \text { value } \\
0.74\end{array}$} \\
\hline & 397 & $89.01 \%$ & 293 & $88.25 \%$ & \\
\hline $302 / 272$ & 18 & $4.04 \%$ & 17 & $5.12 \%$ & 0.47 \\
\hline $302 / 243$ & 29 & $6.50 \%$ & 19 & $5.72 \%$ & 0.65 \\
\hline $272 / 243$ & 1 & $0.22 \%$ & 1 & $0.30 \%$ & 0.83 \\
\hline $243 / 243$ & 1 & $0.22 \%$ & 2 & $0.60 \%$ & 0.40 \\
\hline Homozygotes & 398 & $89.24 \%$ & 295 & $88.86 \%$ & 0.87 \\
\hline Heterozygotes & 48 & $10.76 \%$ & 37 & $11.14 \%$ & 0.87 \\
\hline \multicolumn{6}{|l|}{ Alleles } \\
\hline 243 & 32 & $3.59 \%$ & 24 & $3.61 \%$ & 0.98 \\
\hline 272 & 19 & $2.13 \%$ & 18 & $2.71 \%$ & 0.46 \\
\hline 302 & 841 & $94.28 \%$ & 622 & $93.67 \%$ & 0.62 \\
\hline
\end{tabular}

Table 2 Genotype frequency, allele distribution, and homozygote proportion for MNS16A in the peri-centenarian and control groups, stratified by gender

\begin{tabular}{|c|c|c|c|c|c|c|c|c|c|c|}
\hline \multirow{2}{*}{$\frac{\text { Genotype }}{}$} & \multicolumn{2}{|c|}{$\begin{array}{l}\text { Peri-centenarian female } \\
(N=322)\end{array}$} & \multicolumn{2}{|c|}{ Control female $(N=149)$} & \multirow{2}{*}{$\frac{P \text { value }}{0.28}$} & \multicolumn{2}{|c|}{$\begin{array}{l}\text { Peri-centenarian male } \\
(N=124)\end{array}$} & \multicolumn{2}{|c|}{ Control male $(N=183)$} & \multirow{2}{*}{$\frac{P \text { value }}{0.51}$} \\
\hline & 288 & $89.44 \%$ & 137 & $91.95 \%$ & & 109 & $87.90 \%$ & 156 & $85.25 \%$ & \\
\hline $302 / 272$ & 12 & $3.73 \%$ & 6 & $4.03 \%$ & 0.87 & 6 & $4.84 \%$ & 11 & $6.01 \%$ & 0.66 \\
\hline $302 / 243$ & 21 & $6.52 \%$ & 5 & $3.36 \%$ & 0.16 & 8 & $6.45 \%$ & 14 & $7.65 \%$ & 0.69 \\
\hline $272 / 243$ & 0 & $0.00 \%$ & 1 & $0.67 \%$ & 0.14 & 1 & $0.81 \%$ & 0 & $0.00 \%$ & 0.22 \\
\hline $243 / 243$ & 1 & $0.31 \%$ & 0 & $0.00 \%$ & 0.50 & 0 & $0.00 \%$ & 2 & $1.09 \%$ & 0.24 \\
\hline Homozygotes & 289 & $89.75 \%$ & 137 & $91.95 \%$ & 0.45 & 109 & $87.90 \%$ & 158 & $86.34 \%$ & 0.69 \\
\hline Heterozygotes & 33 & $10.25 \%$ & 12 & $8.05 \%$ & 0.45 & 15 & $12.10 \%$ & 25 & $13.66 \%$ & 0.69 \\
\hline \multicolumn{11}{|l|}{ Alleles } \\
\hline 243 & 23 & $3.57 \%$ & 6 & $2.01 \%$ & 0.20 & 9 & $3.63 \%$ & 18 & $4.92 \%$ & 0.44 \\
\hline 272 & 12 & $1.86 \%$ & 7 & $2.35 \%$ & 0.62 & 7 & $2.82 \%$ & 11 & $3.01 \%$ & 0.89 \\
\hline 302 & 609 & $94.57 \%$ & 285 & $95.64 \%$ & 0.49 & 232 & $93.55 \%$ & 337 & $92.08 \%$ & 0.49 \\
\hline
\end{tabular}

allele [21,26], possibly because it is rare in human populations [21]. In a previous study in Chinese population, the frequency of the 333-bp allele was only $0.06 \%$ in 798 cases and $0 \%$ in 1019 control individuals [27].

We found no significant differences between the longevity group and the younger control group in terms of proportion of homozygotes, genotype distribution, or allele frequency (all $P$-values $>0.05$; Table 1 ). To investigate any potential effect of gender, we divided the two groups into four: female peri-centenarian, male peri-centenarian, female control, and male control. All groups were in HardyWeinberg equilibrium, and there were no significant differences in genotype distribution or allele frequency when stratified by gender (all $P$-values $>0.05$; Table 2 ).

It is well established that the TERT gene and its MNS16A polymorphism play an important role in regulating telomerase activity [21]. In addition, different MNS16A lengths are reported to be associated with cancer risk [21,27-29]. However, aging is a very complex process, and the role of telomerase during aging might be different from that in tumorigenesis. This might explain why we did not find an association between the MNS16A polymorphism and longevity.

Even though we included 778 individuals in the present study, it is possible that this sample size is insufficient to detect a significant association in the Chinese population. If this is the case though, it indicates that variation at MNS16A has a minimal effect on the aging process in the Chinese population. Further studies on TERT and other genes that determine telomerase activity, such as TERC, are needed to understand the role of telomerase in the longevity of human populations.

We are grateful to all the participants in this research. This work was supported by the National Basic Research Program of China (2013CB530802), Yunnan Province (2011FA024), the National Natural Science Foundation of China (31100909) and the Chinese Academy of Sciences.

1 Takahashi Y, Kuro OM, and Ishikawa F. Aging mechanisms. Proc Natl Acad Sci USA, 2000, 97: 12407-12408

2 Alonso-Fernandez P, De la Fuente M. Role of the immune system in aging and longevity. Curr Aging Sci, 2011, 4: 78-100

3 Noth R H, Mazzaferri EL. Age and the endocrine system. Clin Geriatr Med, 1985, 1: 223-250

4 Balistreri CR, Candore G, Accardi G, Bova M, Buffa S, Bulati M, Forte GI, Listì F, Martorana A, Palmeri M, Pellicanò M, Vaccarino L, Scola L, Lio D, Colonna-Romano G. Genetics of longevity. Data from the studies on Sicilian centenarians. Immun Ageing, 2012, 9: 8

5 Yuan R, Flurkey K, Meng Q, Astle MC, Harrison DE. Genetic 
regulation of life span, metabolism, and body weight in Pohn, a new wild-derived mouse strain. J Gerontol A Biol Sci Med Sci, 2012, 68: 27-35

6 Mockett RJ, Cockrell JC, Puri S, Nguyen M, Nisa M. Long-lived genotypes for studies of life extension in Drosophila melanogaster. Mech Ageing Dev, 2012, 133: 359-367

7 Mitchell BD, Hsueh WC, King TM, Pollin TI, Sorkin J, Agarwala R, Schäffer AA, Shuldiner AR. Heritability of life span in the Old Order Amish. Am J Med Genet, 2001, 102: 346-352

8 Bollmann FM. The many faces of telomerase: emerging extratelomeric effects. Bioessays, 2008, 30: 728-732

9 Aragona M, Maisano R, Panetta S, Giudice A, Morelli M, La Torre I, La Torre F. Telomere length maintenance in aging and carcinogenesis. Int J Oncol, 2000, 17: 981-989

10 Lansdorp PM. Telomere length and proliferation potential of hematopoietic stem cells. J Cell Sci, 1995, 108(Pt 1): 1-6

11 Ahmed A, Tollefsbol T. Telomeres and telomerase: basic science implications for aging. J Am Geriatr Soc, 2001, 49: 1105-1109

12 Shen JB, Tang JY, Zhao JC, Pan C, Chen J, Zhou X, Wang YP. Telomerase activity and its correlation with the proliferative potential of bone marrow in aplastic anemia in children. Acta Haematol, 2002, 107: 208-212

13 Bernardes de Jesus B, Vera E, Schneeberger K, Tejera AM, Ayuso E, Bosch F, Blasco MA. Telomerase gene therapy in adult and old mice delays aging and increases longevity without increasing cancer. EMBO Mol Med, 2012, 4: 691-704

14 Haussmann MF, Winkler DW, Huntington CE, Nisbet IC, Vleck CM. Telomerase activity is maintained throughout the lifespan of long-lived birds. Exp Gerontol, 2007, 42: 610-618

15 Atzmon G, Cho M, Cawthon RM, Budagov T, Katz M, Yang X, Siegel G, Bergman A, Huffman DM, Schechter CB, Wright WE, Shay JW, Barzilai N, Govindaraju DR, Suh Y. Evolution in health and medicine Sackler colloquium: genetic variation in human telomerase is associated with telomere length in Ashkenazi centenarians. Proc Natl Acad Sci USA, 2010, 107(Suppl 1): 1710-1717

16 Houben JM, Giltay EJ, Rius-Ottenheim N, Hageman GJ, Kromhout D. Telomere length and mortality in elderly men: the Zutphen Elderly Study. J Gerontol A Biol Sci Med Sci, 2011, 66: 38-44

17 Feng J, Funk WD, Wang SS, Weinrich SL, Avilion AA, Chiu CP, Adams RR, Chang E, Allsopp RC, Yu J. The RNA component of human telomerase. Science, 1995, 269: 1236-1241

18 Deng Y, Chang S. Role of telomeres and telomerase in genomic instability, senescence and cancer. Lab Invest, 2007, 87: 1071-1076
19 Meyerson M, Counter CM, Eaton EN, Ellisen LW, Steiner P, Caddle SD, Ziaugra L, Beijersbergen RL, Davidoff MJ, Liu Q, Bacchetti S, Haber DA, Weinberg RA. hEST2, the putative human telomerase catalytic subunit gene, is up-regulated in tumor cells and during immortalization. Cell, 1997, 90: 785-795

20 Nakamura TM, Morin GB, Chapman KB, Weinrich SL, Andrews WH, Lingner J, Harley CB, Cech TR. Telomerase catalytic subunit homologs from fission yeast and human. Science, 1997, 277: 955-959

21 Wang L, Soria JC, Chang YS, Lee HY, Wei Q, Mao L. Association of a functional tandem repeats in the downstream of human telomerase gene and lung cancer. Oncogene, 2003, 22: 7123-7129

22 Li H, Wang CY, Wang JX, Tang NL, Xie L, Gong YY, Yang Z, Xu LY, Kong QP, Zhang YP. The neck-region polymorphism of DC-SIGNR in peri-centenarian from Han Chinese population. BMC Med Genet, 2009, 10: 134

23 Xie L, Gong YY, Lian SG, Yang J, Yang Y, Gao SJ, Xu LY, Zhang YP. Absence of association between SNPs in the promoter region of the insulin-like growth factor 1 (IGF-1) gene and longevity in the Han Chinese population. Exp Gerontol, 2008, 43: 962-965

24 Xie L, Gong Y Y, Lian S G, Yang J, Gao SJ, Xu LY, Zhang YP. A microsatellite polymorphism in IGF1 gene promoter and longevity in a Han Chinese population. BMC Res Notes, 2010, 3: 55

25 Rousset F. genepop'007: a complete re-implementation of the genepop software for Windows and Linux. Mol Ecol Resour, 2008, 8: 103-106

26 Wang Y, Hu Z, Liang J, Wang Z, Tang J, Wang S, Wang X, Qin J, Wang X, Shen H. A tandem repeat of human telomerase reverse transcriptase (hTERT) and risk of breast cancer development and metastasis in Chinese women. Carcinogenesis, 2008, 29: 1197-1201

27 Zhang Y, Zhang H, Zhai Y, Wang Z, Ma F, Wang H, Li P, Zhang Y, $\mathrm{Yu}$ L, Cui Y, He F, Zhou G. A functional tandem-repeats polymorphism in the downstream of TERT is associated with the risk of nasopharyngeal carcinoma in Chinese population. BMC Med, 2011, 9: 106

28 Hofer P, Baierl A, Feik E, Führlinger G, Leeb G, Mach K, Holzmann K, Micksche M, Gsur A. MNS16A tandem repeats minisatellite of human telomerase gene: a risk factor for colorectal cancer. Carcinogenesis, 2011, 32: 866-871

29 Wang L, Wang L E, Mao L, Spitz MR, Wei Q. A functional variant of tandem repeats in human telomerase gene was associated with survival of patients with early stages of non-small cell lung cancer. Clin Cancer Res, 2010, 16: 3779-3785

Open Access This article is distributed under the terms of the Creative Commons Attribution License which permits any use, distribution, and reproduction in any medium, provided the original author(s) and source are credited. 